\title{
Control of contamination of agricultural machinery motor oil pollution by optoelectronic method
}

\author{
Natalia Kochkovaya ${ }^{1, *}$, Vladimir Semenov ${ }^{1}$, Yuriy Asstaturov ${ }^{1}$, Yuriy Khanzhonkov ${ }^{2}$, and \\ Irina Usova $^{1}$ \\ ${ }^{1}$ Institute of Technologies (branch) of DSTU in Volgodonsk, 16, Mira avenue, 347386, Volgodonsk, \\ Rostov region, Russia \\ ${ }^{2}$ College of Economics and Service of Institute of Service and Business (branch) of DSTU in \\ Shakhty, 51, Voroshilov street, 346500, Shakhty, Rostov region, Russia
}

\begin{abstract}
A new device for controlling the quality of motor oil of agricultural machines is proposed. To increase the information content of the output data and the possibility of uninterrupted automated control, as well as to increase the accuracy, efficiency and reliability of measurements, the device uses an optoelectronic method based on the "drip test" method.
\end{abstract}

\section{Introduction}

Nowadays because of intensive development of agricultural engineering the issues of friction, lubrication and wear are very urgent and their immediate solution is of paramount importance.

During the operation of the friction units of machines and mechanisms the properties of the lubricants presented in tribological conjugations change as contamination occurs with mechanical impurities, water, products of parts wear and oxidation.

Motor oils are characterized by dust contamination because of air sucked for combustion and the fuel.

As the period of exploitation of oil increases, the amount of mechanical impurities in it including suspended metal particles (products of wear of parts of the cylinder-piston group) and carbon monoxide (insoluble oxidation products) of nature in it increases too. In this case carbon monoxide particles are distributed evenly in the oil layer and particles of metal nature as particles with a higher density are distributed mainly in the lower layers of oil in the crankcase when the engine is turned off.

Water accumulates in the working oils it enters from the combustion chamber with bursting gases. The accumulation of water in oil increases corrosion and impairs lubricity. Additives introduced into the oil are also triggered to improve its operational properties and it also leads to a decrease in alkaline number and deterioration of washing properties.

According to the State standard 10541-78 the content of mechanical impurities in pure motor oils should not be higher than $0.015 \%$. The limiting indicator of the content of solids

\footnotetext{
*Corresponding author: kochkovaya@mail.ru
} 
in working oils is from 1 to $3 \%$ depending on the type of engine.

Controlling the main indicators that characterize the properties of oils it is possible to determine the suitability of the oil for use. When exploiting a faulty or overloaded engine the oil may lose its margin of quality. On the contrary it may be in good condition at the time of replacement.

Analysis of oil pollution can be based on various methods: vibroacoustic, electrical, optical, spectral etc. [1-15]. A perspective direction is the development of devices that implement optoelectronic methods which make it possible to carry out uninterrupted automated control, to improve the accuracy, efficiency and reliability of measurements [16].

\section{Optoelectronic device for controlling engine oil quality}

A sufficiently informative and widely used organoleptic method is the so called "drip test method", which consists in applying a drop of the test oil to filter paper and then analyzing the color, pattern and uniformity of the spreading of oil on a paper chromatogram, measuring the diameter of the droplet zones, and studying the components " drip test". At the same time, the analysis of the results of the evaluation of oils by this method can be automated using modern means of control.

The authors have developed an effective device for controlling the quality of motor oil. The scheme of an optoelectronic device for controlling engine oil quality is shown in Figure 1.

The optoelectronic device for controlling the quality of motor oil contains a lighting block 8 , a block for capturing an image and an image processing block, a control circuit for the lighting block, an electromechanical valve for dispensing oil from the crankcase with an electromechanical valve control unit 15 , a stepper motor 12 , two coils 4 with filter paper tape 10, lens 9, CCD-matrix 7, analog-to-digital converter 17, DSP processor 18, temperature sensor 11 , computer 23 , digital indicator 24 , interface to connect to external devices 25 .

The device operates as follows. The device works periodically (once a week, per month or by mileage). A computer 23 through a digital-analog device 16 and an electromechanical valve control device 15 provides a control signal for an electromechanical valve 15 for dosing oil 2 from the crankcase of the engine 1, and this control signal is supplied after the engine is stopped and at the time when the oil temperature detected by the temperature sensor 11 is $50^{\circ} \mathrm{C}$. In this case from the temperature sensor 11 through the amplifier 13 and the analog-to-digital converter 14, information about the temperature of the oil enters the computer 23 . 


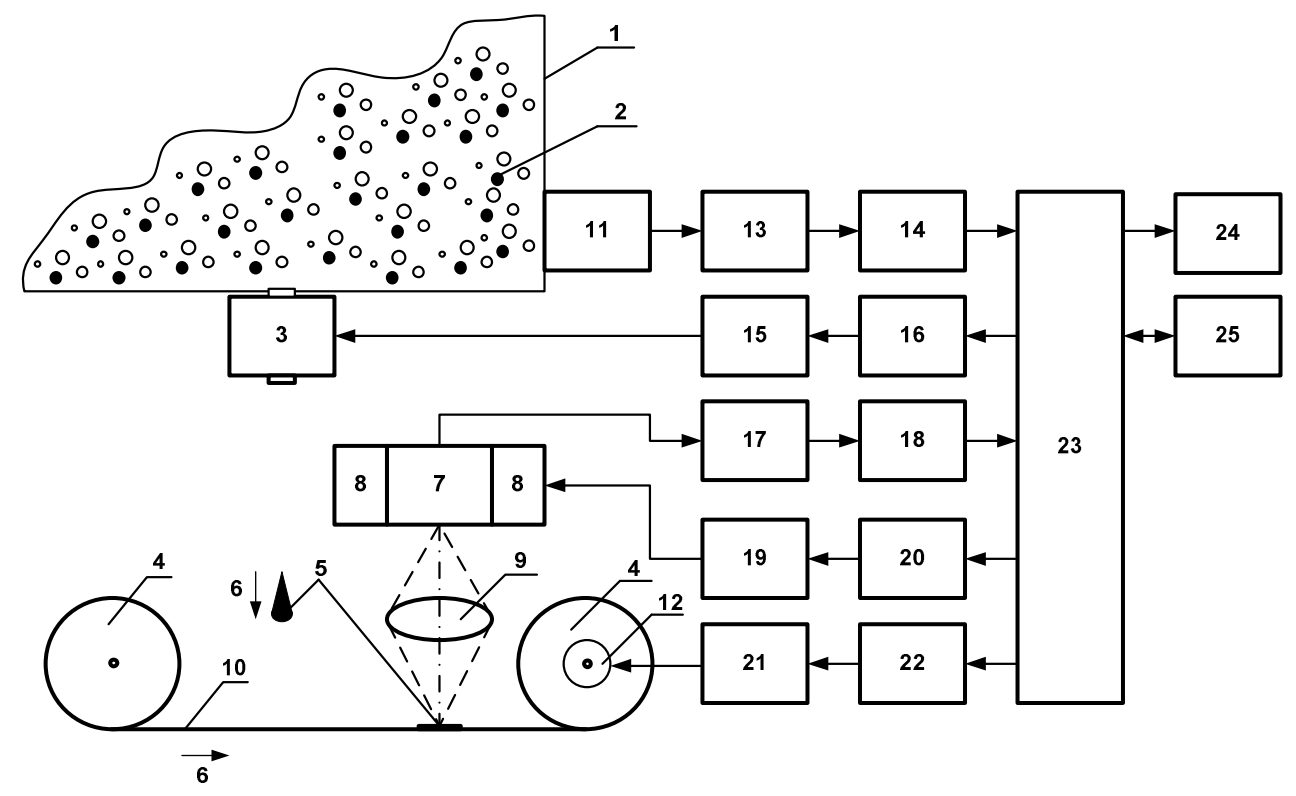

Fig. 1. The scheme of an optoelectronic device for controlling engine oil quality.

At the time of opening of the electromechanical valve for dispensing oil 3 by the control unit 15 from the crankcase of the engine 1, oil 2 in the form of a drop 5 is sent to the filter paper belt 10 and spreading on it for 10 minutes, after which the computer 23 using an analog-to-digital converter 22 and the control unit of the stepper motor 21 includes a stepper motor with which the reel for the tape 4 moves the tape from the filter paper in the 6 direction to the image capture position.

Then the computer 23 using the digital-to-analog converter 20 and the control unit of the lighting device 19 includes a lighting block 8 made of LEDs. The image of an oil drop using a lens 9 and a CCD matrix 7 is digitized in an analog-to-digital converter 17 and enters the DSP processor 18 which performs image processing according to a given algorithm:

1) Classic - according to the ratios of the diameters of the obtained rings;

2) Using Fourier transformation.

The essence of the classic method is that the digital chromatogram of the analyzed oil is quantified by the dispersing ability (DS) according to the formula:

$$
\mathrm{DS}=1-\frac{d^{2}}{D^{2}}
$$

where $d$ is the average diameter of the core together with the zone of the ring, mm;

$D$ is the average diameter of the diffusion zone, $\mathrm{mm}$

On a digital chromotogram the diameters of the three drop zones are measured, their color and pattern are determined, the oil spreading uniformity and the four components of the "drop test" are studied:

- the core or center of the droplet corresponding to the primary zone of the droplet before it spreads over the paper (all heavy insoluble solids settle here);

- the marginal zone (dark/black ring) bordering the core with poorly soluble organic impurities in oil. This ring is absent both with pure oil and with very dirty oil, and the core has a uniform color;

- diffusion zone - a wide gray ring behind the core - through the marginal zone of the oil 
with light dissolved organic impurities;

- a ring of pure oil is the outermost light ring if a loss of detergent-dispersant additives begins to appear in it. This ring is an infrequent phenomenon.

When DS $>0.3$ - the oil is working, and when DS $<0.3$ - the oil is not working.

The Fourier transformation is carried out in two ways:

- Discrete transformation of the central line signal in the oil slick image of a digital chromotogram by the expression:

$$
X_{k}=\sum_{n=0}^{N-1} x_{n} e^{-\frac{2 \pi i}{N} \cdot k n}=\sum_{n=0}^{N-1} x_{n} \cdot\left[\cos \left(\frac{2 \pi k n}{N}\right)-i \cdot \sin \left(\frac{2 \pi k n}{N}\right)\right]
$$

where $N$ is the number of signal values measured a period, as well as the number of decomposition components;

$x_{n}$ is values of the signal at discrete time points $\mathrm{n}=0, \ldots, N-1$;

$k$ is the frequency index, $k=0, \ldots, N-1$.

The resulting harmonics of the discrete Fourier transformation $\mathrm{X}_{\mathrm{k}}$ are taken into account when determining the quality of the oil.

- Using the discrete cosine Fourier transformation of a chromotogram as a sum of complex exponential functions of variable amplitude, frequency and phase.

Two-dimensional discrete cosine transformation of matrix $A$ with dimensions $M x N$ according to the expression:

$$
B_{p q}=\alpha_{p} \alpha_{q} \sum_{m=0}^{M-1} \sum_{n=0}^{N-1} A_{m n} \cos \frac{\pi(2 m+1) p}{2 M} \cos \frac{\pi(2 n+1) q}{2 N},
$$

where $0 \leq \mathrm{p} \leq \mathrm{M}-1$ and $0 \leq \mathrm{q} \leq \mathrm{N}-1$;

$$
\alpha_{p}=\left\{\begin{array}{l}
\frac{1}{\sqrt{M}}, \text { if } \mathrm{p}=0 ; \\
\sqrt{\frac{2}{M}}, \text { if } 1 \leq p \leq \mathrm{M}-1 .
\end{array} \quad \alpha_{q}=\left\{\begin{array}{l}
\frac{1}{\sqrt{N}}, \text { if } \mathrm{q}=0 \\
\sqrt{\frac{2}{N}}, \text { if } 1 \leq q \leq \mathrm{N}-1 .
\end{array}\right.\right.
$$

The values of $B_{p q}$ are the coefficients of the discrete cosine transform of the matrix A. The coefficients of the discrete cosine transform of $B_{p q}$ are taken into account when determining the quality of the oil.

The results of image processing according to the above expressions using the algorithm are implemented by the DSP processor 18 and enter the computer 23.

Registration and processing of the image of an oil drop is carried out in 10, 60, 120 minutes and in a day. The obtained data are averaged by a computer 23 and, as a result of digital processing and comparison of readings with existing image standards, the computer 23 generates a measurement result in the form of an integral indicator of engine oil contamination for output to a digital indicator 24 , as well as for remote transmission of the result to external devices through an interface with external devices 25

The use of the developed optoelectronic device for controlling the quality of motor oil of agricultural machines provides the following advantages: the possibility of uninterrupted automated control, improving the accuracy, efficiency and reliability of measurements. It allows to control the quality of work of the internal combustion engine, the remaining service resource of the oil before it is replaced, and timely to detect wear products of ICE tribological conjugations. 


\section{Conclusion}

An optoelectronic device for controlling the quality of motor oils of agricultural machines has been developed.

The proposed optoelectronic device for monitoring the quality of motor oils allows to increase the information content of the data for assessing the contamination of engine oil, the accuracy, efficiency and reliability of measurements, as well as provide the possibility of uniuterrupted automated control.

\section{References}

1. T. Eggers, H. Dobrinski, J. Stürmann, T. Niemann, Global Powertrain Congress 2010, GPC 2010 MUNICH, Oil pressure, level \& condition sensors for efficient oil\&engine management (Conference Paper) 57, 112-121 (2010)

2. X. Zhi-Na, W. Jiu-Xiang, Q. Jun, Open Petroleum Engineering Journal 5(1), 58-62 (2012)

3. K. Durdag, J. Andle, Tribology and Lubrication Technology 66(2), 40-47 (2010)

4. A. Wolak, G. Zając, Measurement: Journal of the International Measurement Confederation 113, 53-61 (2018)

5. V. Gryazin, I. Bagautdinov, K. Kozlov, V. Belogusev, Engineering for Rural Development 17, 943-947 (2018)

6. N. Dupuy, Z. Brahem, S. Amat, J. Kister, Applied Spectroscopy 69(10), 1137-1143 (2015)

7. J.C.L. Alves, R.J. Poppi, Journal of Near Infrared Spectroscopy 20(4), 419-425 (2012)

8. A. Rista, E. Zanaj, B. Zanaj, Proceedings of 2019 8th International Conference on Modern Power Systems, MPS 2019, Automatic control systems in oil processing industry, 8759730 (2019)

9. E. Förster, C.C. Fraenza, J. Küstner, H. Nirschl, G. Guthausen, Measurement: Journal of the International Measurement Confederation 137, 673-682 (2019)

10. F.C. Barbosa, SAE Technical Papers, F127082 (2016)

11. N. Dupuy, Z. Brahem, S. Amat, J. Kister, Applied Spectroscopy 69(10), 1137-1143 (2015)

12. V. Jaedicke, C. Kasseck, N.C. Gerhardt, H. Welp, M.R. Hofmann, Frontiers in Optics 2010/Laser Science XXVI, OSA Technical Digest (CD) FTuY2 (2010)

13. M.P.L. Sentis, F. R.A. Onofri, F. Lamadie, Optics Express 25(2), 867-873 (2017)

14. M.P.L. Sentis, F. R.A. Onofri, F. Lamadie, Optics Letters 43(12), 2945-2948 (2018)

15. S. Nothelfer, F. Foschuni, A. Kienle, Clinical and Preclinical Optical Diagnostics II, SPIE Proceedings EB101, 11074_81 (2019)

16. V.V. Semenov, Y.G. Astsaturov, Y.B. Hanzhonkov, V.I. Finaev, O.B. Spiridonov, ARPN Journal of Engineering and Applied Sciences 12(11), 3573-3577 (2017) 